\title{
Modeling of glass fiber reinforced composites for optimal mechanical properties using teaching learning based optimization and artificial neural networks
}

\author{
Phaneendra Kumar Kopparthi ${ }^{1}$. Vengal Rao Kundavarapu ${ }^{2}$. Venkata Ravishankar Dasari ${ }^{3}$. Venkata Rao Kaki ${ }^{2}$. \\ Bhaskara Rao Pathakokila ${ }^{1}$
}

Received: 6 August 2019 / Accepted: 2 December 2019 / Published online: 23 December 2019

(c) Springer Nature Switzerland AG 2019

\begin{abstract}
The present work is aimed at determining mechanical properties of chopped strand glass fiber reinforced composite laminates manufactured based on the design of experiments by resin transfer molding at various injection pressures with 4, 5 and 6 layers. Response surface methodology was implemented to the experimental data for evaluating the effect of number of layers and resin injection pressure on mechanical properties and void content. Teaching learning based optimization (TLBO) has been proposed to predict optimal (maximum) mechanical properties of composite by optimizing the number of layers and injection pressure. Artificial neural network (ANN) with feed forward back propagation algorithm was also used to predict the responses and compare with experimental and TLBO results. It was found that the predicted values of responses from TLBO and ANN are good in agreement with experimental results.
\end{abstract}

Keywords Artificial neural network (ANN) · Teaching learning based optimization (TLBO) · Glass fiber reinforced plastic (GFRP) · Resin transfer molding (RTM) · Mechanical properties

\section{Background}

Now-a-days, composite materials have been gaining demand in aerospace, automobile and marine industries due to their high strength, corrosion resistance, rigidity and less weight over metallic components. Resin transfer molding (RTM) is a potential and feasible manufacturing method which can produce composite parts from low to moderate sizes due to its reliable experimental set up and low tooling cost [1-3]. Additionally, it allows higher fiber volume fraction and attracts automotive industry [4] due to its low manufacturing cost. These industries demand composites with excellent mechanical properties. In the field of optimization of fiber reinforced composites, response surface methodology (RSM), Taguchi, grey relation analysis, teaching learning-based optimization (TLBO), genetic algorithm, artificial neural network (ANN) are used for optimization and modeling. RSM was used reliably and exactly to model surface roughness, thrust force and delamination in drilling of carbon/epoxy composites and predict their values [5]. RSM was implemented for metals to make a relationship between cutting parameters, surface roughness and work piece vibration [6]. RSM was used to determine the machining performance under the influence of various parameters of machining. The expressions emerging out of RSM are useful for optimization in other algorithms such as TLBO [7]. RSM was implemented through ellistic teaching learning-based

$\triangle$ Phaneendra Kumar Kopparthi, phani_vec@rediffmail.com | ${ }^{1}$ Department of Mechanical Engineering, Vignan's Lara Institute of Technology \& Science, Vadlamudi, Andhra Pradesh 522 213, India. ${ }^{2}$ Department of Mechanical Engineering, Vignan's Foundation for Science, Technology and Research, Vadlamudi, Andhra Pradesh 522 213, India. ${ }^{3}$ Department of Mechanical Engineering, T.K.R. College of Engineering and Technology, Hyderabad, Telangana 500 079, India. 
optimization (ETLBO) with cutting speed, feed, depth of cut and fiber orientation as the input parameters for determining surface roughness of glass fiber reinforced plastic (GFRP) composite turned on a lathe. The TLBO is a powerful and best method for optimizing process parameters of machining operations in manufacturing industries [8]. This method was employed to optimize spindle speed, depth of cut, feed rate and fiber orientation angle for maximum metal removal rate, minimum surface roughness and cutting force [9].

Furthermore, a biological motivated paradigm of ANN emerged out as an accurate modeling tool for optimum design of metallic as well as composite structures and predicting mechanical properties [10]. A well trained ANN is a useful tool for systematic parametric studies and characterization of failure mechanisms of composites. It was used by several researchers due to reduction in time and cost of required experimental measurements [11-14]. ANN can be used to simulate the relationship between process parameters and performance of composite material by process optimization for its design and prediction of mechanical properties before fabrication/testing [15]. ANN was employed through resilient back propagation to predict the performance of glass fiber composite suffered from cyclic loads with static and cyclic properties as one input layer and fatigue life as output layer [16]. ANN was used to study mechanical properties of carbon/epoxy and glass/epoxy laminates produced in different volume fractions. The composites with fiber orientation angle of $0^{\circ} / 90^{\circ} / \pm 45^{\circ}$ would give better performance [17].

A multilayer feed forward ANN with back propagation was implemented to expect the nonlinear behavior of composite laminate subjected to cyclic loads and establish accurate relationship between input parameters and the number of cycles to failure. This has been the most popular and commonly used tool due to its acceptable generating capabilities [18]. A back propagation neural network was used in ANN architecture for short fiber/polyamide laminates fabricated by injection process. The material compositions and mechanical properties were considered as inputs for different outputs [11, 19].

To the authors' knowledge, researchers focused on RSM for optimizing the process variables and maximizing responses without constraints in the field of composites because this tool does not allow constraints. Therefore, the efforts must be continued to implement a multi objective optimization tool allowing constraints for optimizing the process variables to produce quality FRP composites. TLBO is such a tool for optimizing process parameters to maximize the responses. In the present work, TLBO has been used considering both the number of layers and injection pressure as process variables in the fabrication of composites for maximizing their mechanical properties (tensile, flexural and impact strengths) keeping Reynolds number and void content as constraints. Further, ANN was employed to predict the responses for the given input variables and RSM was used to know the interaction effect of input variables on the responses.

\section{Materials and methodology}

The raw materials used in the composite laminates manufactured for the present investigations are E-glass chopped strand fiber mat of $450 \mathrm{gsm}$ (Code: M6450-104) with fiber length $50 \mathrm{~mm}$, diameter $9 \mu \mathrm{m}$ and polyester resin (viscosity: $450 \pm 50 \mathrm{Cp}$ ). Cobalt napthanate and methyl ethyl ketone peroxide were respectively used as accelerator and catalyst in the proportions of 1:1.25. A customized RTM was used to prepare three different composites which consisted of 4, 5 and 6 layers (L) [20]. Each of the three different composites was manufactured at five different pressures $(P)$ of $0.196,0.245,0.294,0.343$ and $0.392 \mathrm{MPa}$ by injecting polyester resin from the center of mold. The laminates had $5 \mathrm{~mm}$ thickness. The calculated fiber volume fractions of the three composites used are $32.13 \%, 40.94 \%$ and $53.2 \%$ for 4,5 and 6 layers respectively [21].

The methodology of present work is organized in four phases as shown in Fig. 1. In phase-1, injection pressure and number of layers were considered as input parameters. Reynolds number $\left(R_{e}\right)$ and void content $\left(V_{c}\right)$ were taken as constraints. Considering these input parameters and constraints, 15 experiments were designed according to multilevel full factorial [22] to fabricate composites using RTM shown in Fig. 2 for determining tensile strength $\left(\sigma_{t}\right)$ as per ASTM D 638, flexural strength $\left(\sigma_{f}\right)$ as per ASTM D 790 and impact strength $\left(\sigma_{i}\right)$ as per ASTM D 256 standards. In addition to these, void content $\left(V_{c}\right)$ was also quantified as per ASTM D 2734-94 standards in order to study its effect on mechanical properties of composites. The corresponding Reynolds numbers $\left(R_{e}\right)$ were also determined based on flow front velocity of resin [23]. The experimental results of 15 GFRP composite specimens are given in Table 1.

In phase-2, interaction effect of input parameters on responses was studied using RSM. In phase-3, optimal input parameters were determined for optimal mechanical properties of composites using TLBO algorithm. Phase 4 was described with ANN modeling and prediction of responses. The responses obtained from TLBO and ANN were compared with experimental results.

\subsection{Response surface methodology}

RSM is an empirical modeling tool useful for developing, improving and optimizing the response. Response is a 
Fig. 1 Flow diagram

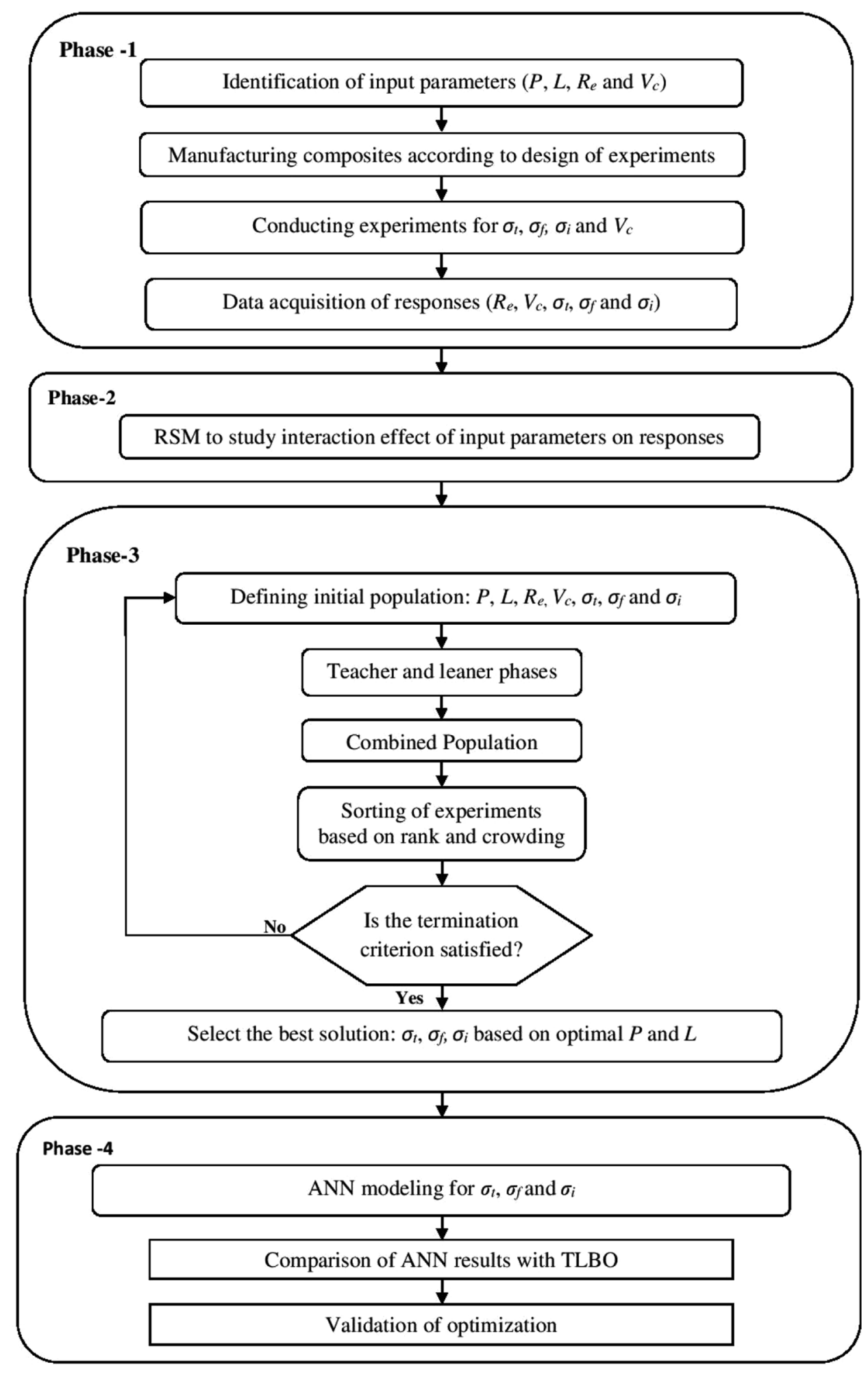

variable dependent on a set of independent variables and the objective is to optimize the response [24]. In this approach, relationship between input and output variables is described as follows [25]: $y=f\left(x_{1}, x_{2}, x_{3} \ldots x_{n}\right) \pm e_{r}$

In the above expression, $y$ is the response, $f$ is the response function, and $x_{1}, x_{2}, \ldots, x_{n}$ are independent variables. $e_{r}$ is 


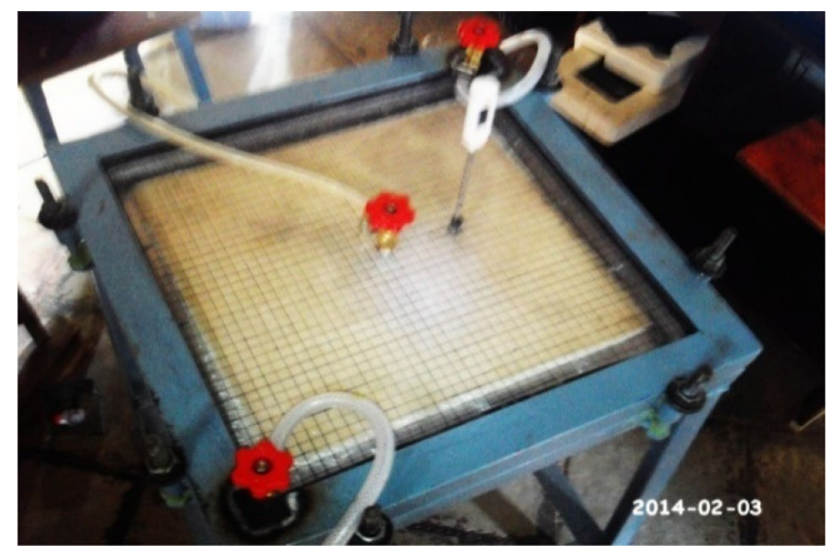

Fig. 2 Customized resin transfer molding

the fitting error. When the mathematical function $(f)$ is unknown, it can be approximated within the bounds of experimental data by a polynomial. This methodology without constraints was employed by Tzeng et al. [26] for deciding optimal parameters by injection molding process to produce short glass fiber and polytetra-fluoro ethylene reinforced polycarbonate composites for enhancing mechanical properties. In this work, Minitab 17 software has been used for model fitting and graphical analysis. ANOVA has also been carried out to identify the significant effect of number of layers and injection pressure on mechanical properties.

\subsection{Teaching learning based optimization}

The problems involving optimization of multiple contradictory objective functions are called as multi-objective problems. Implementation of traditional gradient based optimization methods leads to determine optimal value in the case of a single objective only. However, for multiobjective optimization, one must deal with a problem of determining the best class of solutions among several conflicting objectives simultaneously [27]. Hence, a non-dominated sorting TLBO algorithm was employed for multi objective optimization [28] in the present work to maximize mechanical properties of GFRP composites considering Reynolds number and void content as constraints. This was performed in two phases: teacher phase and learner phase. In TLBO, aim of the teacher is to enhance overall result of the class for subjects taught by him. Number of subjects, number of students and their previous results were taken into consideration to improve mean results of the students. The teacher identifies good learners and allows them for transferring their knowledge to the slow learners for improving overall result. The real-life industrial problems are solved using TLBO. The procedure adapted to the current work is given below in sequential steps.

Step 1 The population, design variables and termination criteria $\left(Z^{\prime}\right)$ are initialized. The best solution was selected based on non-dominance rank, crowding distance assignment $\left(X_{j, k \text { best }, j}\right)$ and mean of each design variable was calculated.

Step 2 Modified values of variables were obtained based on the best solution.

Difference_Mean $_{j, k, i}=r_{i}\left(X_{j, k \text { best }, l}-T_{F} M_{j, i}\right)$ $X_{j, k, i}^{\prime}=X_{j, k, i}+$ Difference_Mean ${ }_{j, k, i}$

Step 3 Modified solutions were combined with the initial solutions.
Table 1 Experimental results of 15 GFRP composite specimens

\begin{tabular}{lllllll}
\hline$L$ & $P(\mathrm{MPa})$ & $R_{e}$ & $V_{c}(\%)$ & $\sigma_{t}(\mathrm{MPa})$ & $\sigma_{f}(\mathrm{MPa})$ & $\sigma_{i}\left(\mathrm{~kJ} / \mathrm{m}^{2}\right)$ \\
\hline 4 & 0.196 & 82.73 & 1.83 & 71.9 & 75.81 & 331.4 \\
4 & 0.245 & 186.14 & 1.75 & 104.16 & 87.36 & 351.58 \\
4 & 0.294 & 330.93 & 1.85 & 103.95 & 76.18 & 312.59 \\
4 & 0.343 & 517.08 & 1.87 & 83.5 & 69.72 & 258.38 \\
4 & 0.392 & 744.59 & 2.05 & 81.41 & 64.73 & 251.98 \\
5 & 0.196 & 37.36 & 1.63 & 86.62 & 84.77 & 400.6 \\
5 & 0.245 & 103.78 & 1.6 & 112.48 & 95.86 & 433.54 \\
5 & 0.294 & 149.44 & 1.54 & 126.81 & 114.23 & 435.94 \\
5 & 0.343 & 330.24 & 1.68 & 119.5 & 118.73 & 392.5 \\
5 & 0.392 & 415.12 & 1.71 & 113.3 & 74.26 & 345.75 \\
6 & 0.196 & 14.2 & 1.5 & 136.84 & 111 & 430.05 \\
6 & 0.245 & 56.81 & 1.52 & 143.58 & 120.73 & 447.58 \\
6 & 0.294 & 127.83 & 1.56 & 144.07 & 126.41 & 467.16 \\
6 & 0.343 & 227.2 & 1.46 & 153.06 & 151.23 & 468.19 \\
6 & 0.392 & 355.1 & 1.58 & 136.7 & 88.9 & 387.09 \\
\hline
\end{tabular}


Step 4 Ranking was given based on non-dominated sorting. Crowding distance was calculated after normalizing objective function to accomplish the teacher phase.

Step 5 The two solutions $X_{\text {total }-P, i}^{\prime}$ and $X_{\text {total }-Q, j}^{\prime}$ were selected randomly.

$$
\begin{aligned}
X_{j, P, i}^{\prime \prime}= & X_{j, P, i}^{\prime}+r_{i}\left(X_{j, P, i}^{\prime}-X_{j, Q, i}^{\prime}\right) \\
& \text { if } X_{\text {total }-P, I}^{\prime} \text { is better than } X_{\text {total }-Q, i}^{\prime} \text { otherwise } \\
X_{j, P, i}^{\prime \prime}= & X_{j, P, i}^{\prime}+r_{i}\left(X_{j, Q, i}^{\prime}-X_{j, P, i}^{\prime}\right) .
\end{aligned}
$$

Step 6 The new solutions of step 5 were combined with the solutions obtained after teacher phase (Step 4). The ranking was given based on non-dominated sorting and then crowding distance was calculated.

Step 7 When the termination criterion is satisfied, the non-dominated set of solutions is reported.

\subsection{Artificial neural networks}

Hosseini and Barker [29] reviewed several optimization techniques and concluded that ANN is one of the effective tools of optimization. ANN model for responses in terms of independent variables is described in Eq. (2). Vectors $(x)$ and $(w)$ are used to represent inputs and synapses efficiencies respectively. Therefore, the magnitude of neuron output is calculated with the Eq. (2) [30]:

$Y=f(y)=f\left(\sum_{i} w_{i} \cdot x_{i}\right)=f(w . x)=f\left(w^{T} \cdot x\right)$

A feed forward multilayer perceptron architecture (2-83 ) was used in this work for modeling of mechanical properties. This architecture consisted of two neurons in input, three neurons in output and eight neurons in hidden layers. The network was trained by adapting weights to the connections between neurons in each layer.

In the present work, RSM was used to analyze the experimental results for identifying the significance of process parameters on responses. TLBO method was adopted to optimize the process parameters for maximization of responses. In addition to these, ANN was employed to validate the results of TLBO.

\section{Results and discussion}

\subsection{Analysis of variance}

In the present study, analysis of variance (ANOVA) was carried out at $95 \%$ of confidence level to analyze the experimental data of Reynolds number, void content, tensile, flexural and impact strengths. The sources having $P$ values less than 0.05 and $F$ values greater than 4 are identified as significant parameters [6]. Table 2 represents ANOVA for Reynolds number, void content, tensile, flexural and impact strengths with linear, square and two factor interaction models. Linear, square and two factor interaction models were observed to be significant for Reynolds number. Number of layers, its square and its interaction with pressure had significance on Reynolds number. Models of linear, number of layers and pressure were noted to be significant on void content. Linear and square models were observed as significant sources for tensile and flexural strengths. Number of layers and square of pressure were noticed as significant models for tensile strength. Number of layers and square of pressure were identified as significant parameters for flexural strength. Linear, square and two factor interaction models were also found to be significant for impact strength. Number of layers, pressure, their squares and their interaction had significance on impact strength.
Table 2 Analysis of variance for five responses (Reynolds

\begin{tabular}{|c|c|c|c|c|c|c|c|c|c|c|c|}
\hline \multirow[t]{2}{*}{ Source } & \multirow[t]{2}{*}{$d f$} & \multicolumn{2}{|c|}{ ANOVA for $R_{e}$} & \multicolumn{2}{|c|}{ ANOVA for $V_{c}$} & \multicolumn{2}{|c|}{ ANOVA for $\sigma_{t}$} & \multicolumn{2}{|c|}{ ANOVA for $\sigma_{f}$} & \multicolumn{2}{|c|}{ ANOVA for $\sigma_{i}$} \\
\hline & & F value & $p$ value & F value & $p$ value & F value & $p$ value & F value & $p$ value & F value & $p$ value \\
\hline Model & 5 & 12.95 & 0.001 & 20.04 & 0.000 & 21.94 & 0.000 & 6.12 & 0.010 & 40.00 & 0.000 \\
\hline Linear & 2 & 22.79 & 0.000 & 47.25 & 0.000 & 47.54 & 0.000 & 10.81 & 0.004 & 83.88 & 0.000 \\
\hline $\mathrm{P}$ & 1 & 4.75 & 0.057 & 84.35 & 0.011 & 1.97 & 0.194 & 0.30 & 0.594 & 22.08 & 0.001 \\
\hline L & 1 & 40.83 & 0.000 & 10.16 & 0.000 & 93.10 & 0.000 & 21.32 & 0.001 & 145.6 & 0.000 \\
\hline Square & 2 & 6.42 & 0.019 & 2.42 & 0.144 & 7.27 & 0.013 & 4.37 & 0.047 & 13.48 & 0.002 \\
\hline$P * P$ & 1 & 0.57 & 0.469 & 2.54 & 0.145 & 13.79 & 0.005 & 8.67 & 0.016 & 17.24 & 0.002 \\
\hline$L^{*} \mathrm{~L}$ & 1 & 12.26 & 0.007 & 2.31 & 0.163 & 0.75 & 0.410 & 0.08 & 0.784 & 9.73 & 0.012 \\
\hline $2 \mathrm{FI}$ & 1 & 6.35 & 0.033 & 0.85 & 0.380 & 0.08 & 0.790 & 0.24 & 0.637 & 5.27 & 0.047 \\
\hline$P * L$ & 1 & 6.35 & 0.033 & 0.85 & 0.380 & 0.08 & 0.790 & 0.24 & 0.637 & 5.27 & 0.047 \\
\hline Error & 9 & & & & & & & & & & \\
\hline Total & 14 & & & & & & & & & & \\
\hline
\end{tabular}
number, void content, tensile, flexural and impact strengths) 
In the present study, statistical significance of the obtained models was developed using ANOVA to generate response plots (Fig. 3) for experimental data of Reynolds number, void content, tensile, flexural and impact strengths. Response surfaces of Fig. $3 a$, b indicate the effect of both number of layers and resin injection pressure on Reynolds number and void content respectively. Reynolds number increased with increase of resin injection pressure and decrease of number of layers. This was happened due to transformation of flow pattern in resin from transition to turbulent as reported by Jean et al. [31]. Figure $3 \mathrm{~b}$ represents decrease in void content with increase in number of layers and decrease in injection pressure. The percent of voids in the composite decreased with increasing number of layers at same injection pressure due to formation of uniform flow front through small pore spaces of the fiber. Further, the void content decreased with decrease of injection pressure due to Reynolds number of resin flow less than or equal to 300 . The similar trend of void formation was also reported by Chang et al. [32].

From the experimental results, void volume fractions of $1.75 \%, 1.54 \%$, and $1.46 \%$ were noticed to be minimum at pressures $0.245,0.294,0.343 \mathrm{MPa}$ for 4,5 and 6 layered composites respectively. These pressures were considered as optimal injection pressures in the present study as the composites exhibited better mechanical properties due to better impregnation of fiber with resin caused by low percent of void content.

The response surfaces in Fig. 3c-e describe the variations in tensile, flexural and impact strengths respectively with respect to both resin injection pressure and number of layers. They also represent maximum strengths gained by the composites. For 4, 5 and 6 layered composites, the maximum tensile strengths were noticed as 104.16, 126.81 and $153.06 \mathrm{MPa}$ at the respective injection pressures of $0.245,0.294$ and $0.343 \mathrm{MPa}$ respectively. Increase in injection pressure beyond the optimal value led to reduction in tensile strength of the composite as reported by Patel et al. [33] for glass fiber/polyester composite. At the same injection pressures, the respective composites had maximum flexural strengths of $87.36,120.73$ and $151.23 \mathrm{MPa}$. Flexural strength also decreased beyond the optimal pressure due to increase of void content present in the composite as noticed by Karbhari et al. [34]. The composites also had maximum impact strengths of $351.58,435.94$ and $468.19 \mathrm{~kJ} / \mathrm{m}^{2}$. Although all the three types of composites exhibited maximum mechanical properties, of them 6 layered composites manufactured at injection pressure $0.343 \mathrm{MPa}$ gave maximum tensile, flexural and impact strengths due to less content of voids present in it.

The quadratic polynomial equation representing response source $(y)$ developed by RSM for mechanical
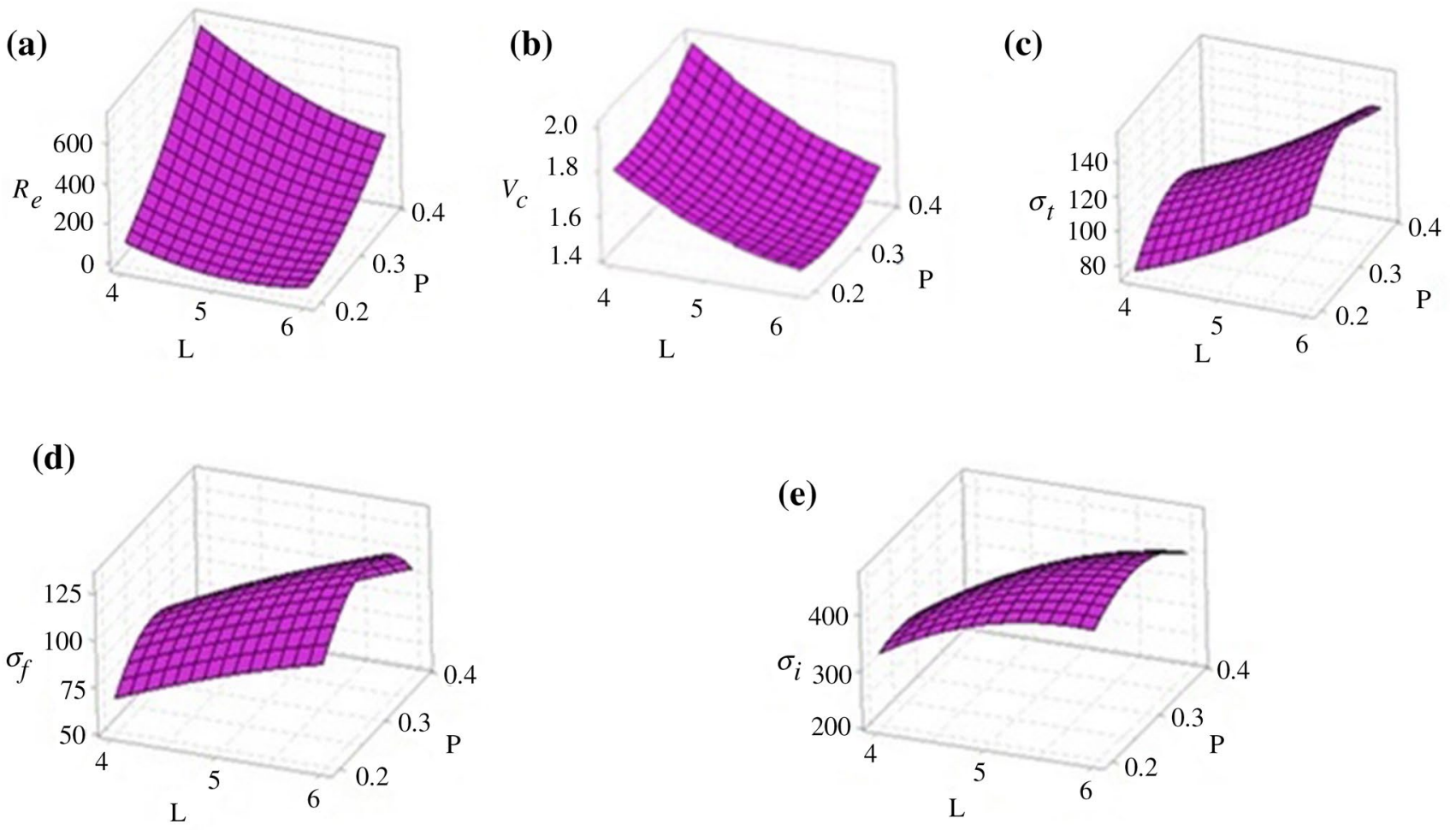

Fig. 3 Response surfaces for the effect of $L$ and $P$ on $\mathbf{a} R_{e} \mathbf{b} V_{c^{\prime}} \mathbf{c} \sigma_{t}, \mathbf{d} \sigma_{f}$ and $\mathbf{e} \sigma_{i}$ 
properties of composites in terms of input parameters [35] is given hereunder.

$y=C_{0}+C_{1} \cdot L+C_{2} \cdot P+C_{11} \cdot L \cdot L+C_{22} \cdot P \cdot P+C_{12} \cdot L \cdot P$

In order to determine the regression coefficients, several experimental design techniques are available. The estimated regression coefficients, $t$ values and $p$ values are given in Table 3. The significance of each model term has been verified using $p$ value. A $p$ value less than 0.05 indicates a significant model term. From Table 3 , the two independent variables, second order of those variables and interaction effect of layers and pressures represent significant model terms on responses.

\subsection{Teaching learning based optimization}

TLBO technique has been employed to optimize number of layers and pressure for the manufacturing of composite to gain required mechanical properties. A non-dominated sorting teaching learning-based optimization (NSTLBO) algorithm has been used for assessing the influence of number of layers and injection pressure on the quality of GFRP laminate with two objective functions for minimization of Reynolds number, void content and maximization of tensile, flexural and impact strengths of composites. Mathematical models for Reynolds number, void content, tensile, flexural and impact strengths were developed with experimental data using regression analysis.

Objective functions Minimize $R_{e}=88-108 L+2373 P$ and $V_{c}=2.364-0.1830 \mathrm{~L}+0.748 \mathrm{P}$.
Maximize $\sigma_{t}=-33.7+26.93 L+46.2 P, \sigma_{f}=-4.6$ $+22.45 \mathrm{~L}-35.1 \mathrm{P}$ and $\sigma_{i}=120.0+69.4 \mathrm{~L}-293 \mathrm{P}$.

Constraints Reynolds number $1 \leq R_{e} \leq 300$ and void content $0 \leq V_{c} \leq 1.46$.

Parameter bounds $4 \leq L \leq 6$ and $0.196 \leq P \leq 0.392 \mathrm{MPa}$.

Table 4 indicates initial population as per design of experiments and average values of input parameters. Constraints $Z_{R_{e}}, Z_{V_{c}}$ and overall constraint violation $Z^{\prime}$ mentioned in the same table were calculated using Eqs. (4)-(6).

$Z_{R_{e}}=R_{e}-300$

$Z_{V_{c}}=V_{c}-1.46$

$Z^{\prime}=\frac{Z_{R_{e}}}{\left(Z_{R_{e}}\right)_{\max }}+\frac{Z_{V_{c}}}{\left(Z_{V_{c}}\right)_{\max }}$

$\left(z_{R_{e}}\right)_{\text {max }}=444.59$ and $\left(Z_{V_{c}}\right)_{\text {max }}=0.59$ were taken from Table 4 to calculate $Z^{\prime}$ value. The difference_mean for the layers and pressure were calculated using input variables in the 1 st rank. Random numbers for $L$ and $P$ were selected as 0.91 and 0.67 respectively. $T_{f}$ was taken as 1 to calculate difference_mean for the input parameters as follows [28].

Difference_mean for $L=0.91(6-5)=0.91$

Difference_mean for $P=0.67(0.343-0.294)=0.0328$

New input parameters, their corresponding layers and pressure were calculated as follows.

Table 3 Estimated regression coefficients, $t$ values and $p$ values

\begin{tabular}{|c|c|c|c|c|c|c|}
\hline \multicolumn{4}{|l|}{$V_{c}$} & \multicolumn{3}{|l|}{$\sigma_{t}$} \\
\hline Term & Coef & $t$ value & $p$ value & Coef & $t$ value & $p$ value \\
\hline$C_{0}$ & 1.342 & 1.98 & 0.079 & 121.86 & 25.41 & 0 \\
\hline$C_{1}$ & -2.518 & -6.39 & 0 & 26.93 & 9.65 & 0 \\
\hline$C_{2}$ & 0.992 & 2.18 & 0.057 & 4.53 & 1.41 & 0.194 \\
\hline$C_{11}$ & 2.39 & 3.5 & 0.007 & 4.18 & 0.86 & 0.41 \\
\hline$C_{22}$ & 0.581 & 0.76 & 0.469 & -20.23 & -3.71 & 0.005 \\
\hline$C_{12}$ & -1.404 & -2.52 & 0.033 & 1.08 & 0.27 & 0.79 \\
\hline \multicolumn{4}{|l|}{$\sigma_{f}$} & \multicolumn{3}{|l|}{$\sigma_{i}$} \\
\hline Term & Coef & $t$ value & $p$ value & Coef & $t$ value & $p$ value \\
\hline$C_{0}$ & 110.82 & 14.34 & 0 & 424.97 & 43 & 0 \\
\hline$C_{1}$ & 22.45 & 4.99 & 0.001 & 69.41 & 12.07 & 0 \\
\hline$C_{2}$ & -3.44 & -0.66 & 0.524 & -31.21 & -4.7 & 0.001 \\
\hline$C_{11}$ & -0.36 & -0.05 & 0.964 & -31.07 & -3.12 & 0.012 \\
\hline$C_{22}$ & -26.51 & -3.02 & 0.014 & -46.6 & -4.15 & 0.002 \\
\hline$C_{12}$ & 2.61 & 0.41 & 0.691 & 18.67 & 2.3 & 0.047 \\
\hline
\end{tabular}


Table 4 Initial population

\begin{tabular}{llllllllllll}
\hline S.no. & $L$ & $P$ & $R_{e}$ & $V_{c}$ & $\sigma_{t}(\mathrm{MPa})$ & $\sigma_{f}(\mathrm{MPa})$ & $\sigma_{i}\left(\mathrm{~kJ} / \mathrm{m}^{2}\right)$ & $Z_{R_{e}}$ & $Z_{V_{c}}$ & $Z$ & Rank \\
\hline 1 & 4 & 0.196 & 82.73 & 1.83 & 71.9 & 75.81 & 312.59 & 0 & 0.37 & 0.6271186 & 10 \\
2 & 4 & 0.245 & 186.14 & 1.75 & 104.16 & 87.36 & 351.58 & 0 & 0.29 & 0.4915254 & 9 \\
3 & 4 & 0.294 & 330.93 & 1.85 & 103.95 & 76.18 & 331.4 & 30.93 & 0.39 & 0.7305867 & 12 \\
4 & 4 & 0.343 & 517.08 & 1.87 & 83.5 & 69.72 & 258.38 & 217.08 & 0.41 & 1.1831853 & 13 \\
5 & 4 & 0.392 & 744.59 & 2.05 & 81.41 & 64.73 & 251.98 & 444.59 & 0.59 & 2 & 14 \\
6 & 5 & 0.196 & 37.36 & 1.63 & 86.62 & 84.77 & 400.6 & 0 & 0.17 & 0.2881356 & 6 \\
7 & 5 & 0.245 & 103.78 & 1.6 & 112.48 & 95.86 & 433.54 & 0 & 0.14 & 0.23728814 & 5 \\
8 & 5 & 0.294 & 149.44 & 1.54 & 126.81 & 114.23 & 435.94 & 0 & 0.08 & 0.13559322 & 3 \\
9 & 5 & 0.343 & 330.24 & 1.68 & 119.5 & 118.73 & 392.5 & 30.24 & 0.22 & 0.4408991 & 8 \\
10 & 5 & 0.392 & 415.12 & 1.71 & 113.3 & 74.26 & 345.75 & 115.12 & 0.25 & 0.682664 & 11 \\
11 & 6 & 0.196 & 14.2 & 1.4 & 136.84 & 111 & 430.05 & 0 & 0 & 0 & 1 \\
12 & 6 & 0.245 & 56.81 & 1.52 & 143.58 & 120.73 & 447.58 & 0 & 0.06 & 0.10169492 & 2 \\
13 & 6 & 0.294 & 127.83 & 1.56 & 144.07 & 126.41 & 467.16 & 0 & 0.1 & 0.16949153 & 4 \\
14 & 6 & 0.343 & 227.2 & 1.46 & 153.06 & 151.23 & 468.19 & 0 & 0 & 0 & 1 \\
15 & 6 & 0.392 & 355.1 & 1.58 & 136.7 & 88.9 & 387.09 & 55.1 & 0.12 & 0.3273242 & 7 \\
Mean & 5 & 0.294 & & & & & & & & & \\
\hline
\end{tabular}

$L_{1}=4+(0.91)=5$

$P_{1}=0.196+(0.0328)=0.228=0.245 \mathrm{MPa}$

$R_{e}=88-108(5)+2373(0.245)=129.385$

$V_{c}=2.364-0.1830(5)+0.748(0.245)=1.63226$

$\sigma_{t}=-33.7+26.93(5)+46.2(0.245)=112.269 \mathrm{MPa}$

$\sigma_{f}=-4.6+22.45(5)-35.1(0.245)=99.0505 \mathrm{MPa}$

$\sigma_{i}=120.0+69.4(5)-293(0.245)=395.215 \mathrm{~kJ} / \mathrm{m}^{2}$

Similarly, remaining values were also calculated and values of $Z_{R_{e}}, Z_{V_{c}}$ and $Z^{\prime}$ are given in Table 5 . The initial solution of Table 4 was combined with updated variables and responses given in the Table 5 . The combined population and their ranks given based on $Z^{\prime}$ value are given in Table 6.

From Table 6, fifteen experiments were chosen based on the non-dominance rank and presented in the Table 7. In this section, the interaction was done between 1 and 15, 2 and 14, 3 and 13,4 and 12, 5 and 11 and so on. New input parameters and objective values after interaction are shown in the Table 8.

As it is the maximization function, knowledge was transferred from the students of 1 st rank to 15 th rank. The values 0.81 and 0.79 were selected as random numbers and new input parameters for $L$ and $P$ after interaction between 1 and 15 are as given below.
Table 5 Updated input parameters, responses, constraints and violations (teacher phase)

\begin{tabular}{llllllllll}
\hline$L$ & $P$ & $R_{e}$ & $V_{c}$ & $\sigma_{t}(\mathrm{MPa})$ & $\sigma_{f}(\mathrm{MPa})$ & $\sigma_{i}\left(\mathrm{~kJ} / \mathrm{m}^{2}\right)$ & $Z_{R_{e}}$ & $Z_{V_{c}}$ & $Z^{\prime}$ \\
\hline 5 & 0.245 & 129.385 & 1.63226 & 112.269 & 99.0505 & 395.215 & 0 & 0.17226 & 0.610384 \\
5 & 0.294 & 245.662 & 1.668912 & 114.5328 & 97.3306 & 380.858 & 0 & 0.208912 & 0.740256 \\
5 & 0.343 & 361.939 & 1.705564 & 116.7966 & 95.6107 & 366.501 & 61.939 & 0.245564 & 1.21769 \\
5 & 0.392 & 478.216 & 1.742216 & 119.0604 & 93.8908 & 352.144 & 178.216 & 0.282216 & 2.000034 \\
5 & $0.392^{\mathrm{a}}$ & 478.21 & 1.742216 & 119.06 & 93.89 & 352.144 & 178.21 & 0.282216 & 2 \\
6 & 0.245 & 21.385 & 1.44926 & 139.199 & 121.5005 & 464.615 & 0 & 0 & 0 \\
6 & 0.294 & 137.662 & 1.485912 & 141.4628 & 119.7806 & 450.258 & 0 & 0.025912 & 0.091816 \\
6 & 0.343 & 253.939 & 1.522564 & 143.7266 & 118.0607 & 435.901 & 0 & 0.062564 & 0.221688 \\
6 & 0.392 & 370.216 & 1.559216 & 145.9904 & 116.3408 & 421.544 & 70.216 & 0.099216 & 0.745568 \\
6 & $0.392^{\mathrm{a}}$ & 370.216 & 1.559216 & 145.9904 & 116.3408 & 421.544 & 70.216 & 0.099216 & 0.745568 \\
$6^{\mathrm{a}}$ & 0.245 & 21.385 & 1.44926 & 139.199 & 121.5005 & 464.615 & 0 & 0 & 0 \\
$6^{\mathrm{a}}$ & 0.294 & 137.662 & 1.485912 & 141.4628 & 119.7806 & 450.258 & 0 & 0.025912 & 0.091816 \\
$6^{\mathrm{a}}$ & 0.343 & 253.939 & 1.522564 & 143.7266 & 118.0607 & 435.901 & 0 & 0.062564 & 0.221688 \\
$6^{\mathrm{a}}$ & 0.392 & 370.216 & 1.559216 & 145.9904 & 116.3408 & 421.544 & 70.216 & 0.099216 & 0.745568 \\
$6^{\mathrm{a}}$ & $0.392^{\mathrm{a}}$ & 370.216 & 1.559216 & 145.9904 & 116.3408 & 421.544 & 70.216 & 0.099216 & 0.745568 \\
\hline
\end{tabular}

${ }^{a}$ The value has crossed the limit, hence the bound value was taken 
Table 6 Combined population (teacher phase)

\begin{tabular}{|c|c|c|c|c|c|c|c|c|c|c|}
\hline$L$ & $P$ & $R_{e}$ & $V_{c}$ & $\sigma_{t}(\mathrm{MPa})$ & $\sigma_{f}(\mathrm{MPa})$ & $\sigma_{i}\left(\mathrm{~kJ} / \mathrm{m}^{2}\right)$ & $Z_{R_{e}}$ & $Z_{V_{c}}$ & $Z^{\prime}$ & Rank \\
\hline 4 & 0.196 & 82.73 & 1.83 & 71.9 & 75.81 & 312.59 & 0 & 0.37 & 0.627119 & 12 \\
\hline 4 & 0.245 & 186.14 & 1.75 & 104.16 & 87.36 & 351.58 & 0 & 0.29 & 0.491525 & 10 \\
\hline 4 & 0.294 & 330.93 & 1.85 & 103.95 & 76.18 & 331.4 & 30.93 & 0.39 & 0.730587 & 14 \\
\hline 4 & 0.343 & 517.08 & 1.87 & 83.5 & 69.72 & 258.38 & 217.08 & 0.41 & 1.183185 & 17 \\
\hline 4 & 0.392 & 744.59 & 2.05 & 81.41 & 64.73 & 251.98 & 444.59 & 0.59 & 2 & 19 \\
\hline 5 & 0.196 & 37.36 & 1.63 & 86.62 & 84.77 & 400.6 & 0 & 0.17 & 0.288136 & 7 \\
\hline 5 & 0.245 & 103.78 & 1.6 & 112.48 & 95.86 & 433.54 & 0 & 0.14 & 0.2372881 & 6 \\
\hline 5 & 0.294 & 149.44 & 1.54 & 126.81 & 114.23 & 435.94 & 0 & 0.08 & 0.1355932 & 3 \\
\hline 5 & 0.343 & 330.24 & 1.68 & 119.5 & 118.73 & 392.5 & 30.24 & 0.22 & 0.440899 & 9 \\
\hline 5 & 0.392 & 415.12 & 1.71 & 113.3 & 74.26 & 345.75 & 115.12 & 0.25 & 0.682664 & 13 \\
\hline 6 & 0.196 & 14.2 & 1.4 & 136.84 & 111 & 430.05 & 0 & 0 & 0 & 1 \\
\hline 6 & 0.245 & 56.81 & 1.52 & 143.58 & 120.73 & 447.58 & 0 & 0.06 & 0.1016949 & 2 \\
\hline 6 & 0.294 & 127.83 & 1.56 & 144.07 & 126.41 & 467.16 & 0 & 0.1 & 0.1694915 & 4 \\
\hline 6 & 0.343 & 227.2 & 1.46 & 153.06 & 151.23 & 468.19 & 0 & 0 & 0 & 1 \\
\hline 6 & 0.392 & 355.1 & 1.58 & 136.7 & 88.9 & 387.09 & 55.1 & 0.12 & 0.327324 & 8 \\
\hline 5 & 0.245 & 129.385 & 1.63226 & 112.269 & 99.0505 & 395.215 & 0 & 0.17226 & 0.610384 & 11 \\
\hline 5 & 0.294 & 245.662 & 1.668912 & 114.5328 & 97.3306 & 380.858 & 0 & 0.208912 & 0.740256 & 15 \\
\hline 5 & 0.343 & 361.939 & 1.705564 & 116.7966 & 95.6107 & 366.501 & 61.939 & 0.245564 & 1.217678 & 18 \\
\hline 5 & 0.392 & 478.216 & 1.742216 & 119.0604 & 93.8908 & 352.144 & 178.216 & 0.282216 & 2 & 19 \\
\hline 5 & $0.392^{\mathrm{a}}$ & 478.216 & 1.742216 & 119.06 & 93.89 & 352.144 & 178.216 & 0.282216 & 2 & 19 \\
\hline 6 & 0.245 & 21.385 & 1.44926 & 139.199 & 121.5005 & 464.615 & 0 & 0 & 0 & 1 \\
\hline 6 & 0.294 & 137.662 & 1.485912 & 141.4628 & 119.7806 & 450.258 & 0 & 0.025912 & 0.091816 & 2 \\
\hline 6 & 0.343 & 253.939 & 1.522564 & 143.7266 & 118.0607 & 435.901 & 0 & 0.062564 & 0.221688 & 5 \\
\hline 6 & 0.392 & 370.216 & 1.559216 & 145.9904 & 116.3408 & 421.544 & 70.216 & 0.099216 & 0.745554 & 16 \\
\hline 6 & $0.392^{\mathrm{a}}$ & 370.216 & 1.559216 & 145.9904 & 116.3408 & 421.544 & 70.216 & 0.099216 & 0.745554 & 16 \\
\hline $6^{a}$ & 0.245 & 21.385 & 1.44926 & 139.199 & 121.5005 & 464.615 & 0 & 0 & 0 & 1 \\
\hline $6^{a}$ & 0.294 & 137.662 & 1.485912 & 141.4628 & 119.7806 & 450.258 & 0 & 0.025912 & 0.091816 & 2 \\
\hline $6^{a}$ & 0.343 & 253.939 & 1.522564 & 143.7266 & 118.0607 & 435.901 & 0 & 0.062564 & 0.221688 & 5 \\
\hline $6^{\mathrm{a}}$ & 0.392 & 370.216 & 1.559216 & 145.9904 & 116.3408 & 421.544 & 70.216 & 0.099216 & 0.745554 & 16 \\
\hline $6^{a}$ & $0.392^{\mathrm{a}}$ & 370.216 & 1.559216 & 145.9904 & 116.3408 & 421.544 & 70.216 & 0.099216 & 0.745554 & 16 \\
\hline
\end{tabular}

${ }^{a}$ The value has crossed the limit, hence the bound value was taken

New $L=6+0.81(6-5)=6.81=6^{\mathrm{a}}$

New $P=0.196+0.79(0.196-0.343)=0.0798=0.196^{\mathrm{a}} \mathrm{MPa}$

Similarly, knowledge was transferred from one student to another student in the remaining interactions and the new values are presented in Table 8. Now the input parameters and objective values obtained in teacher phase (Table 7) and leaner phase (Table 8) were again combined and presented in the Table 9 along with ranking based on $Z^{\prime}$ value. Based on the overall constant violation $Z^{1}$, ranks were given to population as in Table 9. The population was reproduced for best rank patterns. The total crowding distances were calculated for all the reproduced solutions of three different responses (tensile, flexural and impact strengths). The solutions corresponding to the maximum total crowding distances represent the optimal solutions of responses. This indicates that the solutions of responses satisfied the termination criteria [36]. The detailed procedure to calculate crowding distances and select best solutions is given below.

As listed in Table 9, there are 8 combinations given first rank based on $Z^{\prime}$ value and their crowding distances were calculated to select best solution with the procedure given below.

\section{Crowding distance $(C D)$ for objective function Step 1 All rank 1 solutions were collected.}

Step 2 The first objective function of tensile strength was considered and arranged in the ascending order irrespective of the remaining objective functions.

Step 3 The maximum and minimum values of the objective function from the entire population were observed. 
Table 7 Candidate solution based on the non-dominance rank (teacher phase)

\begin{tabular}{llllllllllll}
\hline S. no. & $L$ & $P$ & $R_{e}$ & $V_{c}$ & $\sigma_{t}(\mathrm{MPa})$ & $\sigma_{f}(\mathrm{MPa})$ & $\sigma_{i}\left(\mathrm{~kJ} / \mathrm{m}^{2}\right)$ & $Z_{R_{e}}$ & $Z_{V_{c}}$ & $Z^{\prime}$ \\
\hline 1 & 6 & 0.196 & 14.2 & 1.4 & 136.84 & 111 & 430.05 & 0 & 0 & 0 \\
2 & 6 & 0.343 & 227.2 & 1.46 & 153.06 & 151.23 & 468.19 & 0 & 0 & 0 \\
3 & 6 & 0.245 & 21.385 & 1.44926 & 139.199 & 121.5005 & 464.615 & 0 & 0 & 0 \\
4 & $6^{\mathrm{a}}$ & 0.245 & 21.385 & 1.44926 & 139.199 & 121.5005 & 464.615 & 0 & 0 & 0 \\
5 & 6 & 0.245 & 56.81 & 1.52 & 143.58 & 120.73 & 447.58 & 0 & 0.06 & 0.1016949 & 2 \\
6 & 6 & 0.294 & 137.662 & 1.485912 & 141.4628 & 119.7806 & 450.258 & 0 & 0.025912 & 0.091816 & 2 \\
7 & $6^{\mathrm{a}}$ & 0.294 & 137.662 & 1.485912 & 141.4628 & 119.7806 & 450.258 & 0 & 0.025912 & 0.091816 & 2 \\
8 & 5 & 0.294 & 149.44 & 1.54 & 126.81 & 114.23 & 435.94 & 0 & 0.08 & 0.1355932 & 3 \\
9 & 6 & 0.294 & 127.83 & 1.56 & 144.07 & 126.41 & 467.16 & 0 & 0.1 & 0.1694915 \\
10 & 6 & 0.343 & 253.939 & 1.522564 & 143.7266 & 118.0607 & 435.901 & 0 & 0.062564 & 0.221688 & 5 \\
11 & $6^{\mathrm{a}}$ & 0.343 & 253.939 & 1.522564 & 143.7266 & 118.0607 & 435.901 & 0 & 0.062564 & 0.221688 & 5 \\
12 & 5 & 0.245 & 103.78 & 1.6 & 112.48 & 95.86 & 433.54 & 0 & 0.14 & 0.2372881 & 6 \\
13 & 5 & 0.196 & 37.36 & 1.63 & 86.62 & 84.77 & 400.6 & 0 & 0.17 & 0.288136 \\
14 & 6 & 0.392 & 355.1 & 1.58 & 136.7 & 88.9 & 387.09 & 55.1 & 0.12 & 0.327324 & 8 \\
15 & 5 & 0.343 & 330.24 & 1.68 & 119.5 & 118.73 & 392.5 & 30.24 & 0.22 & 0.440899 & 9 \\
\hline
\end{tabular}

${ }^{\text {a } T h e ~ v a l u e ~ h a s ~ c r o s s e d ~ t h e ~ l i m i t, ~ h e n c e ~ t h e ~ b o u n d ~ v a l u e ~ w a s ~ t a k e n ~}$

Table 8 New values of $L, P, \sigma_{t}, \sigma_{f}, \sigma_{i}, R_{e}, V_{c}$ and violations (learner phase)

\begin{tabular}{|c|c|c|c|c|c|c|c|c|c|c|c|}
\hline S. no. & $L$ & $P$ & $R_{e}$ & $V_{c}$ & $\sigma_{t}(\mathrm{MPa})$ & $\sigma_{f}(\mathrm{MPa})$ & $\sigma_{i}\left(\mathrm{~kJ} / \mathrm{m}^{2}\right)$ & $Z_{R_{e}}$ & $Z_{V_{c}}$ & $Z^{\prime}$ & Interaction \\
\hline 1 & $6^{a}$ & $0.196^{\mathrm{a}}$ & 14.2 & 1.4 & 136.84 & 111 & 430.05 & 0 & 0 & 0 & 1 and 15 \\
\hline 2 & 6 & 0.343 & 253.939 & 1.522564 & 143.7266 & 118.0607 & 435.901 & 0 & 0.062564 & 0.221688 & 2 and 14 \\
\hline 3 & $6^{\mathrm{a}}$ & 0.294 & 137.662 & 1.485912 & 141.4628 & 119.7806 & 450.258 & 0 & 0.025912 & 0.091816 & 3 and 13 \\
\hline 4 & $6^{a}$ & 0.245 & 21.385 & 1.44926 & 139.199 & 121.5005 & 464.615 & 0 & 0 & 0 & 4 and 12 \\
\hline 5 & $6^{a}$ & 0.343 & 253.939 & 1.522564 & 143.7266 & 118.0607 & 435.901 & 0 & 0.062564 & 0.221688 & 5 and 11 \\
\hline 6 & 6 & 0.343 & 253.939 & 1.522564 & 143.7266 & 118.0607 & 435.901 & 0 & 0.062564 & 0.221688 & 6 and 10 \\
\hline 7 & $6^{a}$ & 0.294 & -94.892 & 1.412608 & 136.9352 & 123.2204 & 478.972 & 0 & 0 & 0 & 7 and 9 \\
\hline 8 & 6 & 0.245 & 21.385 & 1.44926 & 139.199 & 121.5005 & 464.615 & 0 & 0 & 0 & 8 and 1 \\
\hline 9 & 6 & 0.343 & 253.939 & 1.522564 & 143.7266 & 118.0607 & 435.901 & 0 & 0.062564 & 0.221688 & 9 and 2 \\
\hline 10 & 6 & $0.392^{\mathrm{a}}$ & 370.216 & 1.559216 & 145.9904 & 116.3408 & 421.544 & 70.216 & 0.099216 & 0.745554 & 10 and 3 \\
\hline 11 & $6^{a}$ & $0.392^{\mathrm{a}}$ & 370.216 & 1.559216 & 145.9904 & 116.3408 & 421.544 & 70.216 & 0.099216 & 0.745554 & 11 and 4 \\
\hline 12 & 6 & 0.245 & 21.385 & 1.44926 & 139.199 & 121.5005 & 464.615 & 0 & 0 & 0 & 12 and 5 \\
\hline 13 & 6 & 0.294 & 137.662 & 1.485912 & 141.4628 & 119.7806 & 450.258 & 0 & 0.025912 & 0.091816 & 13 and 6 \\
\hline 14 & $6^{a}$ & 0.343 & 253.939 & 1.522564 & 143.7266 & 118.0607 & 435.901 & 0 & 0.062564 & 0.221688 & 14 and 7 \\
\hline 15 & 5 & 0.343 & 478.216 & 1.742216 & 119.0604 & 93.8908 & 421.544 & 178.216 & 0.282216 & 2 & 15 and 8 \\
\hline
\end{tabular}

${ }^{\mathrm{a}}$ The value has crossed the limit, hence the bound value was taken

Step 4 For the best and worst solutions of objective function, crowding distance was assigned to be infinity $(\infty)$. The crowding distance $C D_{22}^{1}$ was calculated with the following expression.

$$
\begin{aligned}
& C D_{22}^{1}=0+\frac{\left(\sigma_{t}\right)_{3}-\left(\sigma_{t}\right)_{1}}{\left(\sigma_{t}\right)_{\max }-\left(\sigma_{t}\right)_{\min }} \\
& C D_{22}^{1}=0+\frac{139.19-136.84}{153.06-136.84}=0.145436
\end{aligned}
$$

$C D_{22}^{1}$ represents crowding distance for the first objective function of 22nd sample. Where $\left(\sigma_{t}\right)_{1}$ and $\left(\sigma_{t}\right)_{3}$ represent tensile strengths of $1 \mathrm{st}$ and $3 \mathrm{rd}$ samples respectively. $\left(\sigma_{t}\right)_{\max }$ and $\left(\sigma_{t}\right)_{\min }$ represent maximum and minimum tensile strengths respectively.

Step 5 For the second objective function, steps 4 and 5 were followed and $C D_{22}^{2}$ was determined as follows. 
Table 9 Combined population (learner phase)

\begin{tabular}{|c|c|c|c|c|c|c|c|c|c|c|c|}
\hline S. no. & $L$ & $P$ & $R_{e}$ & $V_{c}$ & $\sigma_{t}(\mathrm{MPa})$ & $\sigma_{f}(\mathrm{MPa})$ & $\sigma_{i}\left(\mathrm{~kJ} / \mathrm{m}^{2}\right)$ & $Z_{R_{e}}$ & $Z_{V_{c}}$ & $Z^{\prime}$ & $\overline{\text { Rank }}$ \\
\hline 1 & 6 & 0.196 & 14.2 & 1.4 & 136.84 & 111 & 430.05 & 0 & 0 & 0 & 1 \\
\hline 2 & 6 & 0.343 & 227.2 & 1.46 & 153.06 & 151.23 & 468.19 & 0 & 0 & 0 & 1 \\
\hline 3 & 6 & 0.245 & 21.385 & 1.44926 & 139.199 & 121.5005 & 464.615 & 0 & 0 & 0 & 1 \\
\hline 4 & $6^{a}$ & 0.245 & 21.385 & 1.44926 & 139.199 & 121.5005 & 464.615 & 0 & 0 & 0 & 1 \\
\hline 19 & $6^{a}$ & 0.245 & 21.385 & 1.44926 & 139.199 & 121.5005 & 464.615 & 0 & 0 & 0 & 1 \\
\hline 22 & $6^{\mathrm{a}}$ & 0.294 & -94.892 & 1.412608 & 139.9352 & 123.2204 & 478.972 & 0 & 0 & 0 & 1 \\
\hline 23 & 6 & 0.245 & 21.385 & 1.44926 & 139.199 & 121.5005 & 464.615 & 0 & 0 & 0 & 1 \\
\hline 27 & 6 & 0.245 & 21.385 & 1.44926 & 139.199 & 121.5005 & 464.615 & 0 & 0 & 0 & 1 \\
\hline 6 & 6 & 0.294 & 137.662 & 1.485912 & 141.4628 & 119.7806 & 450.258 & 0 & 0.025912 & 0.091816 & 2 \\
\hline 7 & $6^{\mathrm{a}}$ & 0.294 & 137.662 & 1.485912 & 141.4628 & 119.7806 & 450.258 & 0 & 0.025912 & 0.091816 & 2 \\
\hline 18 & $6^{a}$ & 0.294 & 137.662 & 1.485912 & 141.4628 & 119.7806 & 450.258 & 0 & 0.025912 & 0.091816 & 2 \\
\hline 28 & 6 & 0.294 & 137.662 & 1.485912 & 141.4628 & 119.7806 & 450.258 & 0 & 0.025912 & 0.091816 & 2 \\
\hline 5 & 6 & 0.245 & 56.81 & 1.52 & 143.58 & 120.73 & 447.58 & 0 & 0.06 & 0.101695 & 3 \\
\hline 8 & 5 & 0.294 & 149.44 & 1.54 & 126.81 & 114.23 & 435.94 & 0 & 0.08 & 0.135593 & 4 \\
\hline 9 & 6 & 0.294 & 127.83 & 1.56 & 144.07 & 126.41 & 467.16 & 0 & 0.1 & 0.169492 & 5 \\
\hline 10 & 6 & 0.343 & 253.939 & 1.522564 & 143.7266 & 118.0607 & 435.901 & 0 & 0.062564 & 0.221688 & 6 \\
\hline 11 & $6^{a}$ & 0.343 & 253.939 & 1.522564 & 143.7266 & 118.0607 & 435.901 & 0 & 0.062564 & 0.221688 & 6 \\
\hline 16 & $6^{a}$ & $0.196^{\mathrm{a}}$ & 94.892 & 1.412608 & 136.9352 & 123.2204 & 478.972 & 0 & 0.062564 & 0.221688 & 6 \\
\hline 17 & 6 & 0.343 & 253.939 & 1.522564 & 143.7266 & 118.0607 & 435.901 & 0 & 0.062564 & 0.221688 & 6 \\
\hline 20 & $6^{a}$ & 0.343 & 253.939 & 1.522564 & 143.7266 & 118.0607 & 435.901 & 0 & 0.062564 & 0.221688 & 6 \\
\hline 21 & 6 & 0.343 & 253.939 & 1.522564 & 143.7266 & 118.0607 & 435.901 & 0 & 0.062564 & 0.221688 & 6 \\
\hline 24 & 6 & 0.343 & 253.939 & 1.522564 & 143.7266 & 118.0607 & 435.901 & 0 & 0.062564 & 0.221688 & 6 \\
\hline 29 & $6^{a}$ & 0.343 & 253.939 & 1.522564 & 143.7266 & 118.0607 & 435.901 & 0 & 0.062564 & 0.221688 & 6 \\
\hline 12 & 5 & 0.245 & 103.78 & 1.6 & 112.48 & 95.86 & 433.54 & 0 & 0.14 & 0.237288 & 7 \\
\hline 13 & 5 & 0.196 & 37.36 & 1.63 & 86.62 & 84.77 & 400.6 & 0 & 0.17 & 0.288136 & 8 \\
\hline 14 & 6 & 0.392 & 355.1 & 1.58 & 136.7 & 88.9 & 387.09 & 55.1 & 0.12 & 0.327324 & 9 \\
\hline 15 & 5 & 0.343 & 330.24 & 1.68 & 119.5 & 118.73 & 392.5 & 30.24 & 0.22 & 0.440899 & 10 \\
\hline 25 & 6 & $0.392^{\mathrm{a}}$ & 370.216 & 1.559216 & 145.9904 & 116.3408 & 421.544 & 70.216 & 0.099216 & 0.745554 & 11 \\
\hline 26 & $6^{a}$ & $0.392^{\mathrm{a}}$ & 370.216 & 1.559216 & 145.9904 & 116.3408 & 421.544 & 70.216 & 0.099216 & 0.745554 & 11 \\
\hline 30 & 5 & 0.343 & 478.216 & 1.742216 & 119.0604 & 93.8908 & 421.544 & 178.216 & 0.282216 & 2 & 12 \\
\hline
\end{tabular}

aThe value has crossed the limit, hence the bound value was taken

$$
\begin{aligned}
& C D_{22}^{2}=C D_{22}^{1}+\frac{\left(\sigma_{f}\right)_{3}-\left(\sigma_{f}\right)_{1}}{\left(\sigma_{f}\right)_{\max }-\left(\sigma_{f}\right)_{\min }} \\
& C D_{22}^{2}=0.145436+\frac{121.50-111}{151.23-111}=0.884426
\end{aligned}
$$

$C D_{22}^{2}$ represents crowding distance for the second objective function of 22 nd sample. Where $\left(\sigma_{f}\right)_{1}$ and $\left(\sigma_{f}\right)_{3}$ represent flexural strength of samples 1 and 3 respectively. $\left(\sigma_{f}\right)_{\text {max }}$ and $\left(\sigma_{f}\right)_{\text {min }}$ represent maximum and minimum flexural strengths respectively.

Step 6 The procedure was repeated for remaining objective functions.

The objective values were normalized and the crowding distances for tensile strengths were calculated and presented in Table 10. Similarly, the crowding distances for
Table 10 Crowding distance for tensile strength

\begin{tabular}{lllll}
\hline S. no. & $L$ & $P$ & $\sigma_{t}(\mathrm{MPa})$ & $C D-\sigma_{t}$ \\
\hline 1 & 6 & 0.196 & 136.84 & $\infty$ \\
22 & $6^{\mathrm{a}}$ & 0.294 & 136.9352 & 0.145438 \\
3 & 6 & 0.245 & 139.199 & 0.139568 \\
4 & $6^{\mathrm{a}}$ & 0.245 & 139.199 & 0 \\
19 & $6^{\mathrm{a}}$ & 0.245 & 139.199 & 0 \\
23 & 6 & 0.245 & 139.199 & 0 \\
27 & 6 & 0.245 & 139.199 & 0.854562 \\
2 & 6 & 0.343 & 153.06 & $\infty$ \\
\hline
\end{tabular}

${ }^{\text {a }}$ The value has crossed the limit, hence the bound value was taken

flexural and impact strengths were calculated. The total crowding distances were calculated and presented in Table 11. Of all the responses of GFR composites obtained 
Table 11 Total crowding distances for three responses

\begin{tabular}{lllll}
\hline S. no. & $C D-\sigma_{t}$ & $C D-\sigma_{f}$ & $C D-\sigma_{i}$ & $C D$-Total \\
\hline 1 & $\infty$ & $\infty$ & $\infty$ & $\infty$ \\
2 & $\infty$ & $\infty$ & $\infty$ & $\infty$ \\
22 & 0.145438 & 0.884426 & $\infty$ & $\infty$ \\
27 & 0.854562 & 0.897314 & 0.970392 & 2.722268 \\
3 & 0.139568 & 0.40058 & 1.107142 & 1.64729 \\
4 & 0 & 0 & 0 & 0 \\
19 & 0 & 0 & 0 & 0 \\
23 & 0 & 0 & 0 & 0 \\
\hline
\end{tabular}

from TLBO, whose Reynolds number and void content are within the range of constrained values $\left(1 \leq R_{e} \leq 300\right.$ and $\left.0 \leq V_{c} \leq 1.46\right)$ and termination criteria are satisfied, their responses represent the optimal responses.

Based on the crowding distances, four optimal solutions were obtained as given in Table 12 (at S. No. 2, 22, 27 and 1). The lowest value of crowding distance (at S. No. 1) was eliminated due to the crowding distance $(\infty)$ assigned to the highest and lowest values of the responses as in Table 10, which indicates low values of responses for the composite fabricated with 6 layers at $0.196 \mathrm{MPa}$. The input variables in Table 12 are identified as optimal solutions for maximization of objectives for 6 layered composites at injection pressures $0.343,0.294,0.245 \mathrm{MPa}$. Based on this data, it has been noted that the 6 layered composites manufactured at pressure $0.343 \mathrm{MPa}$ had maximum tensile, flexural and impact strengths of $153.06 \mathrm{MPa}, 151.23 \mathrm{MPa}$ and $468.19 \mathrm{~kJ} / \mathrm{m}^{2}$ respectively.

\subsection{Prediction of responses using ANN}

In the present study, an ANN technique was employed to develop prediction model for the responses to validate the results of TLBO. A 2-8-3 neural network represents two nodes in input layer, three nodes in output layer and eight nodes in hidden layer as shown in Fig. 4. In the network, 2 represents number of inputs (number of layers and injection pressure), 3 represents number of responses (tensile, flexural and impact strengths) and 8 represents number of nodes in hidden layer. Number of hidden layers and number of nodes in hidden layer

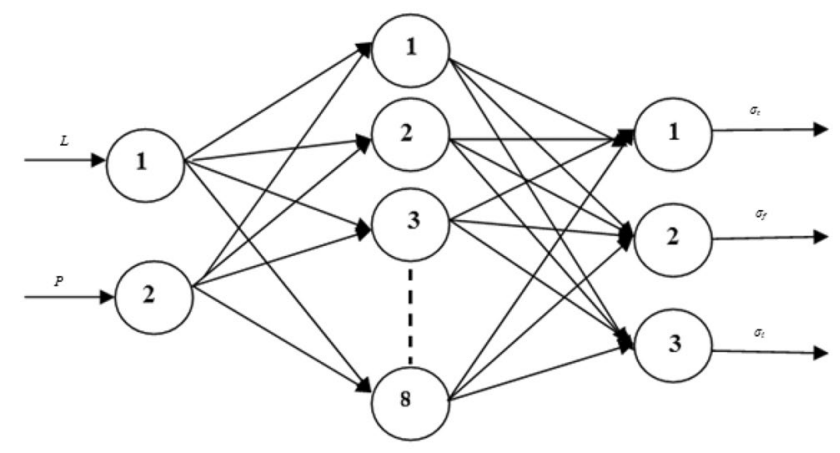

Input Layer Hidden Layer

Output Layer

Fig. 4 ANN 2-8-3 architecture

are estimated by trial and error method to get error less than target error (0.01). A feed forward back propagation algorithm was used to train the neural network [36]. The proposed network was trained with 12 samples at learning rate of 0.7 and a momentum rate of 0.8 and validated with 3 samples. The process of learning was stopped after 51,500 cycles when the average training error was found to be less than the target error 0.01 . The average training was 0.00006967 which is less than the target error 0.01. The learning graph in Fig. 5 was constructed taking learning cycles on $\mathrm{x}$-axis and target error on $y$-axis. All the errors were found to be less than 0.01 as shown in Fig. 5 . The red, blue, green and orange lines represent maximum, minimum, average example and average validating errors respectively. During the training process, 16 was taken as weight for the connections between the input layer and hidden layer and, 24 was taken as weight for the connections between the hidden layer and output layer. After training the network, the responses were predicted for the three optimal solutions. The TLBO and ANN results were compared with the experimental results given in Table 13. It was observed that the results of three methods were found to be in good agreement. From these optimal solutions, it has been observed that the 6 layered composites manufactured at pressure $0.343 \mathrm{MPa}$ had maximum tensile, flexural and impact strengths of $152.65 \mathrm{MPa}, 150.93 \mathrm{MPa}$ and $466.28 \mathrm{~kJ} / \mathrm{m}^{2}$ respectively.
Table 12 Final solutions based on the ranks and crowding distances

\begin{tabular}{llllllllll}
\hline S. no. & $\mathrm{L}$ & $\mathrm{P}$ & $\sigma_{t}(\mathrm{MPa})$ & $\sigma_{f}(\mathrm{MPa})$ & $\sigma_{i}\left(\mathrm{~kJ} / \mathrm{m}^{2}\right)$ & $Z_{R_{e}}$ & $Z_{V_{c}}$ & $Z^{\prime}$ & Rank \\
\hline 2 & 6 & 0.343 & 153.06 & 151.23 & 468.19 & 0 & 0 & 0 & 1 \\
22 & $6^{\mathrm{a}}$ & 0.294 & 139.9352 & 123.2204 & 478.972 & 0 & 0 & 0 & 1 \\
27 & 6 & 0.245 & 139.199 & 121.5005 & 464.615 & 0 & 0 & 0 & 1 \\
1 & 6 & 0.196 & 136.84 & 111 & 430.05 & 0 & 0 & 0 & 1 \\
\hline
\end{tabular}

${ }^{a}$ The value has crossed the limit, hence the bound value was taken 


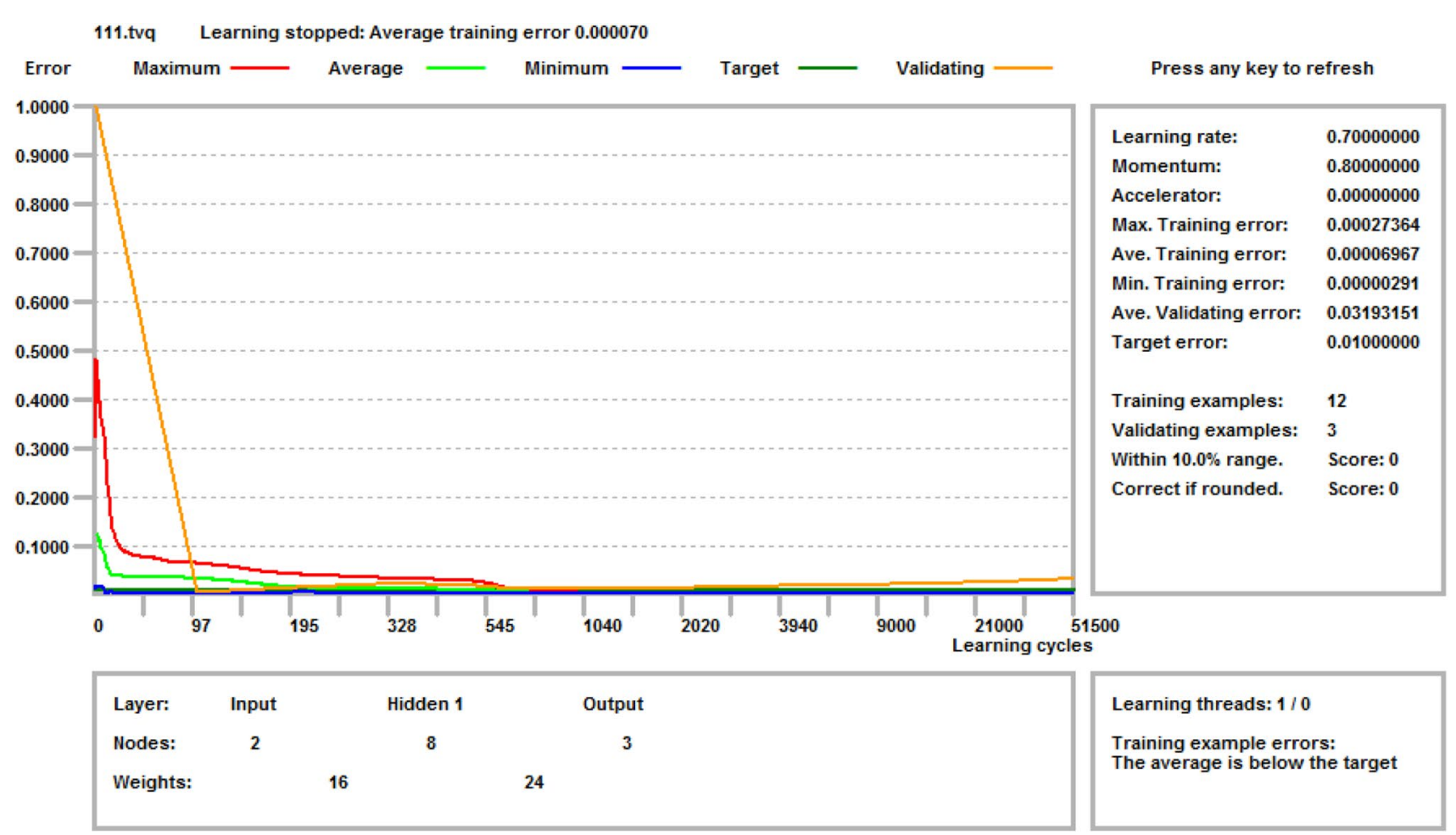

Fig. 5 Learning progress graph with maximum, average and minimum training errors

Table 13 Validation of optimization results with experiments

\begin{tabular}{|c|c|c|c|c|c|c|c|c|c|c|c|}
\hline \multirow[t]{2}{*}{ S.No } & \multirow[t]{2}{*}{$L$} & \multirow[t]{2}{*}{$P$} & \multicolumn{3}{|c|}{$\sigma_{t}(\mathrm{MPa})$} & \multicolumn{3}{|c|}{$\sigma_{f}(\mathrm{MPa})$} & \multicolumn{3}{|c|}{$\sigma_{i}\left(\mathrm{~kJ} / \mathrm{m}^{2}\right)$} \\
\hline & & & TLBO & EXP & ANN & TLBO & EXP & ANN & TLBO & EXP & ANN \\
\hline 2 & 6 & 0.343 & 153.06 & 153.06 & 152.65 & 151.23 & 151.23 & 150.93 & 468.19 & 468.19 & 466.28 \\
\hline 22 & 6 & 0.294 & 139.93 & 144.07 & 151.71 & 123.22 & 126.41 & 148.94 & 478.97 & 467.16 & 464.19 \\
\hline 27 & 6 & 0.245 & 139.19 & 143.58 & 136.84 & 121.50 & 120.73 & 111.04 & 464.61 & 447.58 & 431.67 \\
\hline
\end{tabular}

\section{Conclusion}

The experiments were performed on GFRP laminates with 4, 5 and 6 layers manufactured by RTM process to obtain optimal mechanical properties at different injection pressures $0.196,0.245,0.294,0.343$ and $0.392 \mathrm{MPa}$. ANOVA was implemented to the experimental data for predicting effect of number of layers and injection pressure on mechanical properties. Statistical models RSM, TLBO and ANN were also developed to optimize the number of layers and injection pressure for predicting optimal mechanical properties. The following conclusions are drawn from the present work.

- The experiments reveal that mechanical properties of the composite are affected by resin injection pressure, number of layers and void content. However, the maximum tensile, flexural and impact strengths were obtained at optimal injection pressures of 0.245 , 0.294, $0.343 \mathrm{MPa}$ for 4, 5 and 6 layered composites respectively with minimum void content and Reynolds number less than 300 .

- Based on ANOVA, number of layers and resin injection pressure during the fabrication of composite were proved to be significant on Reynolds number, void content, tensile, flexural and impact strengths.

- TLBO and ANN models were developed for manufacturing GFRP composites by RTM with number of layers and injection pressure as variables. Both models have given maximum mechanical properties for 4,5 and 6 layered composites at their respective optimal injection pressures.

- However, the maximum mechanical properties from TLBO and ANN models were obtained for 6 layered composites at an optimal injection pressure of $0.343 \mathrm{MPa}$ with minimum void content and Reynolds 
number of resin flow less than 300 as observed from experiments.

- Finally, mechanical properties obtained from the models of TLBO and ANN are good in agreement with experimental results.

\section{Compliance with ethical standards}

Conflict of interest Authors declare that they have no conflict of interest.

\section{References}

1. Friedrich K, Almajid AA (2013) Manufacturing aspects of advanced polymer composites for automotive applications. Appl Compos Mater 20:107-128

2. Deleglise M, Le GP, Binetruy C, Krawczak P, Claude B (2011) Modeling of high-speed RTM injection with highly reactive resin with on-line mixing. Compos A 42:1390-1397

3. Luo J, Liang Z, Zhang C, Wang B (2001) Optimum tooling design for resin transfer molding with virtual manufacturing and artificial intelligence. Compos A 32:877-888

4. Kendall KN, Rudd CD, Owen MJ, Middleton V (1992) Characterization of the resin transfer molding process. Compos Manuf 4:235-249

5. Shahrajabian H, Farahnakian M (2013) Modeling and multi-constrained optimization in drilling. Int J Pr Eng Man 14(10):1829-1837

6. Rao KV, Murthy PBGSN (2016) Modeling and optimization of tool vibration and surface roughness in boring of steel using RSM, ANN and SVM. J Intell Manuf. https://doi.org/10.1007/s1084 5-016-1197-y

7. Mehrvar A, Basti A, Jamali A (2016) Optimization of electrochemical machining process parameters: combining response surface methodology and differential evolution algorithm. Proc I Mech Part E J Intell Manuf. https://doi.org/10.1177/095440891665638 7

8. Ramesh R, Lakhan R, Arun P, Santosh C, Nagaraju D (2016) Parametric optimization for turning of GFRP composites using ellistic teaching learning-based optimization (ETLBO). Int J Adv Prod Mech Eng 2(3):25-30

9. Abhishek K (2015) Experimental investigations on machining of CFRP composites: study of parametric influence and machining performance optimization. PhD Thesis, NIT-Rourkela, India

10. Kadi EH (2006) Modeling the mechanical behavior of fiberreinforced polymeric composite materials using artificial neural networks-a review. Compos Struct 73:1-26

11. Zhang Z, Friedrich K, Velten K (2002) Prediction on tribological properties of short fiber composites using artificial neural networks. Wear 252:668-675

12. Fazilat $H$, Ghatarb M, Mazinani ZA, Asadi S, Shiri ME, Kalaee MR (2012) Predicting the mechanical properties of glass fiber reinforced polymers via artificial neural network and adaptive neuro-fuzzy inference system. Comput Mater Sci 58:31-37

13. Zhu J, Shi Y, Feng X, Wang H, Lu X (2009) Prediction on tribological properties of carbon fiber and $\mathrm{TiO}_{2}$ synergistic reinforced polytetrafluoroethylene composites with artificial neural networks. Mater Des 30:1042-1049
14. Bar HN, Bhat MR, Murthy CRL (2004) Identification of failure modes in GFRP using PVDF sensors: an approach. Compos Struct 65:231-237

15. Zhang Z, Friedrich K (2003) Artificial neural networks applied to polymer composites: a review. Compos Sci Technol 63:2029-2044

16. Assadi AM, Kadi EIH, Deiab IM (2010) Predicting the fatigue life of different composite materials using artificial neural networks. Appl Compos Mater 17:1-14

17. Bezerra EM, Ancelotti AC, Pardini LC, Rocco JAFF, Iha K, Ribeiro CHC (2007) Artificial neural networks applied to epoxy composites reinforced with carbon and E-glass fibers: analysis of the shear mechanical properties. Mater Sci Eng A 464:177-185

18. Assaf AY, Kadi EIH (2001) Fatigue life prediction of unidirectional glass fiber/epoxy composite laminae using neural networks. Compos Struct 53:65-71

19. Jiang Z, Gyurova L, Zhang Z, Friedrich K, Schlarb AK (2008) Neural network-based prediction on mechanical and wear properties of short fibers reinforced polyamide composites. Mater Des 29:628-637

20. Bickerton S, Sozer EM, Graham PJ, Advani SG (2000) Fabric structure and mold curvature effects on preform permeability and mold filling in the RTM process part I experiments. Compos Part A Appl Sci 31:423-438

21. Dong C (2014) Experimental investigations on the fiber preform deformation due to mold closure for composites processing. Int J Adv 71:585

22. Jenarthanan MP, Ramesh KS, Jeyapaul R (2015) Modeling of machining force in end milling of GFRP composites using MRA and ANN. Aust J Mech Eng. https://doi.org/10.1080/14484 846.2015.1093227

23. Baker MJ (2011) CFD simulation of flow through packed beds using the finite volume technique. PhD Thesis, University of Exeter, Exeter

24. Myers RH, Montgomery DC (2002) Response surface methodology: process and product optimization using designed experiments, 2nd edn. Wiley, London

25. Montgomery DC (2001) Design and analysis of experiments, 5 th edn. Wiley, New York

26. Tzeng CJ, Yang YK, Lin YH, Tsai CH (2012) A study of optimization of injection molding process parameters for SGF and PTFE reinforced $\mathrm{PC}$ composites using neural network and response surface methodology. Int J Adv Manuf Technol 63:691-704

27. Deb K (2001) Multi-objective optimization using evolutionary algorithms. Wiley, Chichester

28. Rao RV (2016) Teaching learning-based optimization algorithm. Springer, Cham, pp 9-39

29. Hosseini S, Barker K, Ramirez MJE (2016) A review of definitions and measures of system resilience. Relia Eng Sys Saf 45:47-61

30. Kishan M, Chilukuri KM, Sanjay R (1997) Elements of artificial neural networks. The MIT Press, Cambridge

31. Jean SL, Edu R (2008) Porosity reduction using optimized flow velocity in resin transfer molding. Compos Part A Appl Sci Manf 39:1859-1868

32. Chang LL, Kung HW (2000) Resin transfer molding (RTM) process of a high-performance epoxy resin II: effects of process variables on the physical, static and dynamic mechanical behavior. Polym Eng Sci 4:935-943

33. Patel N, Rohatgi V, Lee LJ (1993) Influence of processing and material variables on resin fiber interface in liquid composite molding. Polym Compos 14(2):161-172

34. Karbhari VM, Slotee SG, Steen Kamer DA, Wilkins DJ (1992) Effect of material process and equipment variables on the performance of resin transfer moulded parts. J Compos Manuf 3:143

35. Mousavi SM, Niaei A, Salari D, Panahi PN, Samandari M (2013) Modelling and optimization of Mn/activate carbon for no 
reduction: comparision of RSM and ANN techniques. Environ Technol 34(11):1377-1384

36. Rao KV (2018) A novel approach for minimization of tool vibration and surface roughness in orthogonal turn milling of silicon bronze alloy. Silica. https://doi.org/10.1007/s12633-018-9953-6
Publisher's Note Springer Nature remains neutral with regard to jurisdictional claims in published maps and institutional affiliations. 